Portland State University

PDXScholar

Engineering and Technology Management

Faculty Publications and Presentations

1997

\title{
Selecting the "Best" Using Data Envelopment Analysis
}

Timothy R. Anderson

Portland State University, tim.anderson@pdx.edu

Akin Uslu

Portland State University

Follow this and additional works at: https://pdxscholar.library.pdx.edu/etm_fac

Part of the Operations Research, Systems Engineering and Industrial Engineering Commons Let us know how access to this document benefits you.

\section{Citation Details}

Anderson, T.R., Uslu. A. "Selecting the "Best" Using Data Envelopment Analysist," Innovation in Technology Management - The Key to Global Leadership. PICMET '97: Portland International Conference on Management and Technology, pp.789-793.

This Article is brought to you for free and open access. It has been accepted for inclusion in Engineering and Technology Management Faculty Publications and Presentations by an authorized administrator of PDXScholar. Please contact us if we can make this document more accessible: pdxscholar@pdx.edu. 


\title{
Selecting the "Best" Using Data Envelopment Analysis
}

\author{
Timothy R. Anderson \\ Akin Uslu \\ Engineering Management Program \\ Portland State University \\ Portland, OR 97207-0751 USA
}

\begin{abstract}
One of the most important strengths of Data Envelopment Analysis, (DEA), is that it allows almost complete freedom in the way that each decision making unit, (DMU), evaluates itself relative to its peers. This tends to result in many DMUs receiving a high efficiency score. Particularly when DEA is applied in a decision making context, it may be desirable to select a single option rather than determining the set of efficient alternatives in ranking efficient DMU or to Assist selecting a "best" DMU. Several extensions to DEA have been proposed and used. This paper examines, compares, and integrates a variety of these methods. A less complicated application area is used to investigate the subtleties of DEA cross-efficiency.
\end{abstract}

\section{INTRODUCTION}

One of the most important strengths of Data Envelopment Analysis, (DEA), is that it allows almost complete freedom in the way that each decision making unit, (DMU), evaluates itself relative to its peers. This tends to result in many DMUs receiving a high efficiency score. Particularly when DEA is applied in a decision making context, it is usually desirable to select a single option and this situation does not present a clear result. Several extensions to DEA have been proposed and used for this purpose in the past. This paper examines a variety of these cases. A less complicated application area is used to investigate the subtleties of DEA cross-efficiency.

\section{WEIGHT FLEXIBILITY}

An introduction to DEA is provided in [2]. In this paper we will focus upon the dual, input-oriented, CCR [4] formulation of DEA which is based upon each DMU attempting to find a weighting scheme for inputs and outputs that puts it in its most favorable possible light relative to peers.

This freedom to develop one's own weighting scheme often makes it easy for a DMU to come out with a high score. For example, a DMU that has the highest ratio of one output to an input can simply put all of its weight on that output and input. It will then end up receiving an efficiency score of one and be declared efficient. Since there are as many ratios as there are inputs $(m)$, multiplied by outputs, $(s)$, there could be as many as $m s$ efficient DMUs on the basis of ratios. Since, these DMUs are deemed efficient on the basis of placing a heavy emphasis on one input and one output at the expense of all the other inputs and outputs, they are often examined suspiciously. Often these highly skewed weighting schemes are considered to be invalid.

This issue is considered both one of DEA's greatest strengths and weaknesses and has been examined by many researchers. Another major difficulty when trying to use a DEA approach to select one preferred DMU (or altemative) is that all of the efficient DMUs are tied. A variety of solutions have been offered to solve the problem of ties and unrealistic weighting schemes.

We will begin by revisiting a data set used in [10] that surveyed multiple criteria decision making techniques (MCDM). The omission of DEA from techniques surveyed drew a response [5] that used cross-efficiency to demonstrate how DEA could be used to select a single "best" location for the placement of an electric power plant. This inspired an additional response [11] as well as further work to examine the efficiencies of each input to the outputs rather than all of the inputs at once [13]. All of these studies used the same application and data set. This paper uses the same data set and to examine certain issues in more depth. The definitions of the inputs and outputs are described below. The input and output data are provided in Table II along with results of a basic CCR primal DEA evaluation.

$\begin{array}{ll}x_{1} & \text { Manpower required } \\ x_{2} & \text { Construction costs in } 10^{6} \text { US dollars } \\ x_{3} & \text { Annual maintenance costs in } 10^{6} \text { US dollars } \\ x_{4} & \text { Number of villages to be evacuated } \\ y_{1} & \text { Power Generated in Megawatts } \\ y_{2} & \text { Safety level on a nominal scale }\end{array}$

TABLE I

CASE 1: CCR, INPUT-ORIENTED POWERPLANT SITING ANALySIS

\begin{tabular}{|c|c|c|c|c|c|c|c|c|c|c|c|c|c|}
\hline $\mathbf{k}$ & $x_{1}$ & $x_{2}$ & $x_{3}$ & $x_{4}$ & $y_{1}$ & $\mathrm{Y}_{2}$ & $v_{1}$ & $v_{2}$ & $v_{3}$ & $V_{4}$ & $\mu_{1}$ & $\mu_{2}$ & $\theta_{\mathbf{r}}$ \\
\hline 1 & 80 & 600 & 54 & 8 & 90 & 5 & 0.0057 & 0.0008 & 0.0011 & 0 & 0.0111 & 0 & 1 \\
\hline 2 & 65 & 200 & 97 & 1 & 58 & 1 & 0.0123 & 0.0010 & 0 & 0 & 0.0172 & 0 & 1 \\
\hline 3 & 83 & 400 & 72 & 4 & 60 & 7 & 0.0049 & 0.0014 & 0 & 0 & 0 & 0.1428 & 1 \\
\hline 4 & 40 & 1000 & 75 & 7 & 80 & 10 & 0.0250 & 0 & 0 & 0 & 0 & 0.1000 & 1 \\
\hline 5 & 52 & 600 & 20 & 3 & 72 & 8 & 0.0089 & 0.0008 & 0 & 0 & 0 & 0.1250 & 1 \\
\hline 6 & 94 & 700 & 36 & 5 & 96 & 6 & 0 & 0.0012 & 0.0030 & 0 & 0.0090 & 0.0212 & 1 \\
\hline
\end{tabular}

Solutions for CCR efficient DMUs typically suffer from high degeneracy so the weights, $\mu$ and $v$, are not unique. 
The CCR, input-oriented results in Table I illustrate the difficulty of using a generic DEA model in an MCDM problem. First, each DMU here is considered to be "efficient." Second, the weighting schemes that can be used by each DMU to determine that it is efficient vary considerably. The weights given in Table I are not unique and are shown for illustration purposes only but they do show that several DMUs were efficient on the basis of completely ignoring the annual maintenance costs. In fact, this is a special case but one input, $x_{4}$, may not even be given any weight at all by any DMU. Even a basic knowledge of this application would point out that some DMUs are using unrealistic weighting schemes.

A variety of solutions have been offered to solve the problem of ties and unrealistic weighting schemes. We will examine three methods separately and in combination. These methods include weight restrictions, super-efficiency, and cross-efficiency.

\section{WEIGHT RESTRICTION TECHNIQUES}

\section{A. Explicit Weight Restrictions}

A couple of techniques may be readily apparent to alleviate this problem. The first is a straight forward bounding of the weights that can be applied. This could take the form of a simple statement such as "an additional unit of output 1 is worth at least twice as much as an additional unit of output 2" Several groups have developed methods for implementing this in DEA $[3,7,12]$. A variety of closely related techniques are available to impose weight restrictions. For the sake of this example, we will refer back to the application area.

The second input, $x_{2}$, refers to construction cost in millions of dollars and the third input, $x_{3}$, refers to annual maintenance cost in millions of dollars. These two inputs could be aggregated into a single input based on a present value or annual equivalent calculation. If the analyst cannot identify a single minimum attractive rate of return to calculate the present value or annual equivalent value of these two inputs, an alternate approach could be to use a range of the minimum and maximum plausible interest rates to restrict the possible tradeoffs between capital costs and annually recurring costs. Also we will use a minimum plausible interest rate of $4 \%$ and a maximum of $10 \%$ to develop relative input weight restrictions. Next, we might also attempt to relate the labor requirement to the capital cost. For the sake of argument, we will assure that a labor unit will be considered to be "no more costly" than an extra million dollars in capital costs. Lastly, while a social cost is not given for evacuating a village, it appears to be reasonable to assume that it will have a cost that is equivalent to at least one million dollars in capital cost. The resulting new constraints are included in the primal CCR formulation (1). Note that these constraints will restrict the tradeoffs that a DMU $k$ may make between an additional unit (million $\$$ ) of capital cost $(x 3)$ and annual maintenance cost $(x 4)$ in constructing the weighted virtual input $v X_{k}$.

$$
\begin{aligned}
\max _{v, \mu} \theta_{k} & =\mu Y_{k}, \\
\text { s.t. } & v X_{k}=1, \\
\mu Y_{j} & \leq v X_{j}, \quad j \in[1, \ldots, n] \\
v_{3} & \geq 0.04 v_{2}, \\
& v_{3} \leq 0.01 v_{2}, \\
& v_{1} \leq v_{3}, \\
& v_{4} \geq v_{2}, \\
\mu, v \geq 0 . &
\end{aligned}
$$

The results of the weight restricted evaluations are given in Table II. Note that the number of efficient alternatives $\left(\theta_{k}=1\right)$ decreased as well as the number of times that a DMU completely ignored an input or an output by having a zero input or output weight.

TABLE II

CASE 2: WEIGHT RESTRICTED POWERPLANT SITING ANALYSIS

\begin{tabular}{|c|cccccc|c|}
\hline $\mathrm{k}$ & $\mathrm{v}_{1}$ & $\mathrm{v}_{2}$ & $\mathrm{v}_{3}$ & $\mathrm{v}_{4}$ & $\mu_{1}$ & $\mu_{2}$ & $\theta_{\mathrm{k}}$ \\
\hline 1 & 0.0002 & 0.0016 & 0.0002 & 0.0016 & 0.0051 & 0.0526 & 0.7236 \\
2 & 0 & 0.0047 & 0.0005 & 0.0047 & 0.0172 & 0 & 1 \\
3 & 0 & 0.0024 & 0.0002 & 0.0024 & 0 & 0.1429 & 1 \\
4 & 0.0001 & 0.0006 & 0.0001 & 0.0526 & 0 & 0.0671 & 0.6713 \\
5 & 0.0001 & 0.0012 & 0.0001 & 0.0909 & 0.0046 & 0.0837 & 1 \\
6 & 0.0001 & 0.0009 & 0.0001 & 0.0694 & 0.0035 & 0.0640 & 0.7205 \\
\hline
\end{tabular}

There are still three efficient DMUs or alternatives that we cannot differentiate between. Unfortunately, to guarantee the selection of only one DMU (assuming that each DMUs is linearly independent), it would be necessary to fix the relative weights for inputs and the relative weights for the outputs. If this information were available, DEA would never have even been needed.

It is difficult to draw further restrictions in this application domain without losing credibility. Therefore, we will need to examine additional methods for differentiating between the efficient DMUs.

\section{B. Super-Efficiency}

Another approach is to determine the most outstanding DMU or alternative, which we will refer to as "superefficiency". This idea was first widely disseminated in [1]. In the dual formulation, this can be implemented by removing the constraint that the maximum self-rated efficiency score be equal to one. This means that each DMU can give itself as high a score as possible as long as no other DMU receives a score greater than one makes scores greater than 1.0 possible.

$$
\begin{aligned}
& \max _{\nu, \mu} \theta_{k}=\mu Y_{k}, \\
& \text { s.t. } v X_{k}=1, \\
& \quad \mu Y_{j} \leq v X_{j}, \quad j \in[1, \ldots, n], j \neq k \\
& \quad \mu, \nu \geq 0 .
\end{aligned}
$$


TABLE III

CASE 3: "SUPER-EFFICIENCY" EVALUATION

\begin{tabular}{|c|cccccc|c|}
\hline $\mathrm{k}$ & $\mathrm{v}_{1}$ & $\mathrm{v}_{2}$ & $\mathrm{v}_{3}$ & $\mathrm{v}_{4}$ & $\mu_{1}$ & $\mu_{2}$ & $\theta_{\mathrm{k}}$ \\
\hline 1 & 0.0031 & 0.0010 & 0.0026 & 0 & 0.0114 & 0 & 1.0282 \\
2 & 0 & 0.0033 & 0 & 0 & 0.0416 & 0 & 2.4166 \\
3 & 0 & 0.0025 & 0 & 0 & 0 & 0.1875 & 1.312 \\
4 & 0.0250 & 0 & 0 & 0 & 0 & 0.1625 & 1.625 \\
5 & 0.0048 & 0 & 0.0374 & 0 & 0 & 0.3003 & 2.4025 \\
6 & 0 & 0.0011 & 0.0041 & 0.0115 & 0.0110 & 0 & 1.0627 \\
\hline
\end{tabular}

While Table III shows that super-efficiency develops a unique ordering of the DMUs, the weighting schemes used by each DMU once again vary widely and would appear to be unrealistic. The weights of the super-efficiency model may be similarly restricted and the results are shown in Table IV.

TABLE IV

CASE4: "SUPER-EFFICIENCY" EYALUATION WITH WEIGHT RESTRICTIONS

\begin{tabular}{|c|cccccc|c|}
\hline $\mathrm{k}$ & $\mathrm{v}_{1}$ & $\mathrm{v}_{2}$ & $\mathrm{v}_{3}$ & $\mathrm{v}_{4}$ & $\mu_{1}$ & $\mu_{2}$ & $\theta_{\mathrm{k}}$ \\
\hline 1 & 0.0002 & 0.0016 & 0.0002 & 0.0016 & 0.0051 & 0.0526 & 0.7236 \\
2 & 0 & 0 & 0 & 1 & 0.0417 & 0 & 2.4167 \\
3 & 0 & 0.0025 & 0.0001 & 0.0025 & 0 & 0.1855 & 1.2985 \\
4 & 0.0001 & 0.0006 & 0.0001 & 0.0526 & 0 & 0.0671 & 0.6713 \\
5 & 0 & 0 & 0 & 0.3333 & 0.0029 & 0.1657 & 1.5337 \\
6 & 0.0001 & 0.0009 & 0.0001 & 0.0694 & 0.0035 & 0.0640 & 0.7205 \\
\hline
\end{tabular}

The DMUs are still given a unique ordering but the superefficiency approach tends to reward DMUs that are very different from other DMUs in a particular ratio of output to input. While this may be beneficial to note, if other DMUs follow a more consistent distribution of inputs or outputs, these DMUs would be penalized at the expense of the eccentric DMU. Still, this method does provide a way of differentiating efficient DMUs and also reduces the problem of non-unique weighting schemes being developed.

\section{Cross-Efficiency}

Cross-efficiency provides a fundamentally different perspective on DEA as first detailed in 1986 by [9]. The basic concept of cross-efficiency is for a DMU to use its "selfevaluation" weighting scheme to evaluate its peers and for it to be evaluated by the other DMUs. As in traditional DEA, the DMU being studied, which we denote as DMU $k$, begins by conducting its self-evaluation to cast itself in as positive a light as possible. To make the development of crossefficiency more clear, we will slightly alter the subscripting of the variables. The radial efficiency of DMU $k$ when DMU $\mathrm{k}$ evaluates itself will be denoted as $\theta_{k, k}$.

The second stage is where the cross-efficiency analysis differs from traditional DEA. Given that DMU $k$ has obtained an efficiency score $\theta_{k, k}$, the next step is to evaluate the efficiency of the other DMUs. Recall that if a DMU is radically efficient, it typically has a wide range of weighting schemes that will make it look efficient. An important question is how should the weighting scheme be selected.
DMU $k$ may attempt to make its peers look as bad as possible by selecting a weighting scheme which give them low efficiency scores. This is termed an aggressive formulation. Similarly, it may select a scheme that make the other DMUs look as good as possible which is termed a benevolent formulation.

The first step is the same as a traditional DEA evaluation. The second phase of an aggressive formulation is described in (3).

$$
\begin{array}{ll}
\min _{\nu, \mu} & \sum_{j=1}^{n} \theta_{k, j}, \\
& j \neq k \\
\text { s.t. } & v X_{k}=1, \\
& \theta_{k, j}=\frac{\mu Y_{j}}{v X_{j}} \leq 1, \quad j \in[1, \ldots, n] \\
& \mu Y_{k}=\theta_{k, k}, \\
& \mu, \nu \geq 0 .
\end{array}
$$

Unfortunately, this formulation is a nonlinear problem due to the ratios of weighted inputs and outputs in the objective function. Unlike the traditional DEA ratio model, the DEA cross-efficiency model cannot be fully linearized. To make the model computationally tractable, an approximation to the objective function is used. Rather than trying to minimize the sum of the ratios (each of which corresponds to an efficiency score), the approximation calls for minimizing the sum of the difference between each numerator and denominator. The second phase is demonstrated in (4).

$$
\begin{array}{ll}
\min _{\nu, \mu} & \sum_{j=1}^{n} d_{k, j}, \\
& j \neq k \\
\text { s.t. } & v X_{k}=1, \\
& \mu Y_{j} \leq v X_{j}, \quad j \in[1, \ldots, n] \\
& d_{k, j}=\mu Y_{j}-v X_{j}, \quad j \in[1, \ldots, n] \\
& \mu Y_{k}=\theta_{k, k}, \\
& \mu, \nu \geq 0 .
\end{array}
$$

Alternative approximations to overcome the original nonlinear formation are developed and evaluated in [6]. This indicated that the results are very robust with respect to the approximation method used but a different method may offer slightly improved results. For the sake of this current work, we will use the original approximation [9] shown in formulation (4). The results using the different approximations should be similar.

Cross-efficiency models that attempt to minimize (or maximize) all of the other DMU efficiency scores at once are 
referred to as "blanketed." An additional, albeit more subtle problem, is that the cross-efficiency weights may not be unique. As with the other cases shown, the weights are not guaranteed to be unique. An alternative to the "blanketed" approach termed "targeted" has been developed [9] to overcome this problem. While it provides more repeatable results, it is much more computationally intensive and the results are similar to blanketed results [6].

Using a blanketed aggressive cross-efficiency formulation, [5] showed that these six sites could be differentiated. Case 5 in Table $\mathrm{V}$ shows the results of this basic cross-efficiency model. These results exhibited weight difficulties similar to those discussed earlier. Since cross-efficiency is calculated as the average of the weighted efficiency scores, an unrealistic weighting scheme by one DMU will affect the crossefficiency score for every DMU. Therefore, weight restrictions were also incorporated into the model as suggested in [5].
We also examined incorporating super-efficiency into cross-efficiency with and without weight restrictions. Incorporating super-efficiency into cross-efficiency has interesting properties in that it rewards DMUs for truly exceptional performance with scores of $\theta_{k, k}>1$. This benefit decreases in importance as the number of DMUs increases and cross-efficiency is calculated by averaging a larger number of scores $\theta_{i, k}$. The hybrid model using superefficiency and cross-efficiency together still captures the benefits of an informal "voting" regarding how all of the DMUs value inputs and outputs [8] but still gives truly unique and outstanding DMUs the opportunity to excel. An interesting and potentially important benefit of incorporating super-efficiency into cross-efficiency is that super-efficiency greatly reduces the problem of multiple optima and therefore reduces the effect of different choices in the cross-efficiency modeling choices such as between the aggressive and benevolent formulations.

TABLE V

Cross EFFICIENCY EVALUATIONS

\begin{tabular}{|c|c|c|c|c|c|c|c|c|c|c|c|c|}
\hline \multicolumn{13}{|c|}{ CASE 5: BLANKETED AGGRESSIVE CROSS EFFICIENCY } \\
\hline k & $v_{1}$ & $v_{2}$ & $v_{3}$ & $v_{4}$ & $\mu_{1}$ & $\mu_{2}$ & $\theta_{1}$ & $\theta_{2}$ & $\theta_{3}$ & $\theta_{4}$ & $\theta_{5}$ & $\theta_{6}$ \\
\hline 1 & 0.0005 & 0.0013 & 0.0037 & 0 & 0.0111 & 0 & 1 & 1 & 0.8190 & 0.5669 & 0.9294 & 1 \\
\hline 2 & 0 & 0 & 0 & 1 & 0.0172 & 0 & 0.1940 & 1 & 0.2586 & 0.1970 & 0.4138 & 0.3310 \\
\hline 3 & 0 & 0.0025 & 0 & 0 & 0 & 0.1429 & 0.4762 & 0.2857 & 1 & 0.5714 & 0.7619 & 0.4898 \\
\hline 4 & 0.0250 & 0 & 0 & 0 & 0 & 0.1000 & 0.2500 & 0.0615 & 0.3373 & 1 & 0.6154 & 0.2553 \\
\hline 5 & 0 & 0 & 0.0500 & 0 & 0 & 0.1250 & 0.2315 & 0.0258 & 0.2431 & 0.3333 & 1 & 0.4167 \\
\hline \multirow[t]{2}{*}{6} & 0 & 0.0009 & 0.0099 & 0 & 0.0104 & 0 & 0.8636 & 0.5293 & 0.5793 & 0.5017 & 1 & 1 \\
\hline & & & & & \multicolumn{2}{|c|}{ Average Efficiencies } & 0.5025 & 0.4837 & 0.5395 & 0.5284 & 0.7867 & 0.5821 \\
\hline \multicolumn{13}{|c|}{ CASE 6: CASE 5 WITH WEIGHT RESTRICTIONS } \\
\hline$k$ & $v_{1}$ & $\mathrm{v}_{2}$ & $v_{3}$ & $\mathrm{v}_{4}$ & $\mu_{1}$ & $\mu_{2}$ & $\theta_{1}$ & $\theta_{2}$ & $\theta_{3}$ & $\theta_{4}$ & $\theta_{5}$ & $\theta_{6}$ \\
\hline 1 & 0.0002 & 0.0016 & 0.0002 & 0.0016 & 0.0051 & 0.0526 & 0.72359 & 1 & 1 & 0.5705 & 0.8036 & 0.6983 \\
\hline 2 & 0 & 0 & 0 & 1 & 0.0172 & 0 & 0.19397 & 1 & 0.2586 & 0.1970 & 0.4138 & 0.3310 \\
\hline 3 & 0 & 0.0025 & 0.0001 & 0.0025 & 0 & 0.1429 & 0.47632 & 0.2837 & 1 & 0.5755 & 0.7701 & 0.4937 \\
\hline 4 & 0.0001 & 0.0006 & 0.0001 & 0.0526 & 0 & 0.0671 & 0.41752 & 0.3578 & 1 & 0.6713 & 1 & 0.5686 \\
\hline 5 & 0 & 0 & 0 & 0.3333 & 0 & 0.1250 & 0.23438 & 0.3750 & 0.6563 & 0.5357 & 1 & 0.4500 \\
\hline \multirow[t]{2}{*}{6} & 0.0001 & 0.0009 & 0.0001 & 0.0694 & 0.0035 & 0.0640 & 0.56883 & 1 & 1 & 0.6516 & 1 & 0.7205 \\
\hline & & & & & Average $\mathrm{E}$ & fficiencies & 0.4358 & 0.6694 & 0.8192 & 0.5336 & 0.8313 & 0.5437 \\
\hline \multicolumn{13}{|c|}{ CASE 7: CASE 5 WITH SUPER EFFICIENCY } \\
\hline $\mathbf{k}$ & $v_{1}$ & $v_{2}$ & $v_{3}$ & $v_{4}$ & $\mu_{1}$ & $\mu_{2}$ & $\theta_{1}$ & $\theta_{2}$ & $\theta_{3}$ & $\theta_{4}$ & $\theta_{5}$ & $\theta_{6}$ \\
\hline 1 & 0.0031 & 0.0010 & 0.0027 & 0 & 0.0114 & 0 & 1.0283 & 1 & 0.8022 & 0.6835 & 1 & 1 \\
\hline 2 & 0 & 0 & 0 & 1 & 0.0417 & 0 & 0.4687 & 2.4167 & 0.6250 & 0.4762 & 1 & 0.8000 \\
\hline 3 & 0 & 0.0025 & 0 & 0 & 0 & 0.1875 & 0.6250 & 0.3750 & 1.3125 & 0.7500 & 1 & 0.6429 \\
\hline 4 & 0.0250 & 0 & 0 & 0 & 0 & 0.1625 & 0.4063 & 0.1000 & 0.5482 & 1.6250 & 1 & 0.4149 \\
\hline 5 & 0.0048 & 0 & 0.0375 & 0 & 0 & 0.3003 & 0.6233 & 0.0761 & 0.6786 & 1 & 2.4026 & 1 \\
\hline \multirow[t]{3}{*}{6} & 0 & 0.0011 & 0.0042 & 0.0115 & 0.0111 & 0 & 1 & 1 & 0.8315 & 0.5807 & 1 & 1.0628 \\
\hline & & & & \multirow{2}{*}{\multicolumn{3}{|c|}{$\begin{array}{l}\text { Capped Average Efficiencies } \\
\text { Regular Average Efficiencies }\end{array}$}} & 0.6872 & 0.5919 & 0.7476 & 0.7484 & 1 & 0.8096 \\
\hline & & & & & & & 0.6919 & 0.8280 & 0.7997 & 0.8526 & 1.2338 & 0.8201 \\
\hline \multicolumn{13}{|c|}{ CASE 8: CASE 5 WITH SUPER EFFICIENCY AND WEIGHT RESTRICTIONS } \\
\hline $\mathbf{k}$ & $v_{1}$ & $v_{2}$ & $v_{3}$ & $\mathrm{v}_{4}$ & $\mu_{1}$ & $\mu_{2}$ & $\theta_{1}$ & $\theta_{2}$ & $\theta_{3}$ & $\theta_{4}$ & $\theta_{\mathbf{s}}$ & $\theta_{6}$ \\
\hline 1 & 0.0002 & 0.0016 & 0.0002 & 0.0016 & 0.0051 & 0.0526 & 0.72359 & 1 & 1 & 0.5705 & 0.8036 & 0.6983 \\
\hline 2 & 0 & 0 & 0 & 1 & 0.0417 & 0 & 0.46875 & 2.4167 & 0.6250 & 0.4762 & 1 & 0.8000 \\
\hline 3 & 0 & 0.0025 & 0.0001 & 0.0025 & 0 & 0.1855 & 0.61849 & 0.3684 & 1.2985 & 0.7473 & 1 & 0.6410 \\
\hline 4 & 0.0001 & 0.0006 & 0.0001 & 0.0526 & 0 & 0.0671 & 0.41752 & 0.3578 & 1 & 0.6713 & 1 & 0.5686 \\
\hline 5 & 0 & 0 & 0 & 0.3333 & 0.0029 & 0.1657 & 0.40824 & 1 & 1 & 0.8092 & 1.5337 & 0.7630 \\
\hline \multirow[t]{3}{*}{6} & 0.0001 & 0.0009 & 0.0001 & 0.0694 & 0.0035 & 0.0640 & 0.56883 & 1 & 1 & 0.6516 & 1 & 0.7205 \\
\hline & & & & \multirow{2}{*}{\multicolumn{3}{|c|}{$\begin{array}{l}\text { Capped Average Efficiencies } \\
\text { Regular Average Efficiencies }\end{array}$}} & 0.5342 & 0.7877 & 0.9375 & 0.6544 & 0.9673 & 0.6986 \\
\hline & & & & & & & 0.53424 & 1.0238 & 0.9872 & 0.6544 & 1.0562 & 0.6986 \\
\hline
\end{tabular}


To examine using super efficiency in this manner we also capped the cross-efficiency results by limiting efficiency scores. This was done by substituting a value of 1.0 for scores of $\theta_{k, k}>1$. Capped average results represent these efficiency scores. Another approach would be to simply exclude one's self rated efficiency in calculating cross-efficiencies.

While there is a temptation to simply use crossefficiency in place of weight restrictions, the analyst should be cautioned to be very careful in considering the weights used in the evaluation. Notice that as in the superefficiency case of Table III, many DMUs applied unrealistic weighting schemes in case 5 of Table V. Although [5] did not show the weights used to determine efficiency, they do mention that weight restrictions may be applied to further refine the results. The same weight restrictions discussed earlier were added to the crossefficiency model and the results are given as case 6 in Table V.

A related but more subtle issue was raised in [8]. Green and Doyle state "Evaluating each alternative against a number of sets of weights and averaging the resulting evaluations approximates the effect of evaluating each alternative against the same composite set of weights."

This statement indicates that may be approximated as single stage procedure which determines a single set of fixed weight for determining the cross-efficiency. This underlying and implicit characteristic of cross-efficiency means every DMU is essentially evaluated on the basis of this single fixed weighting scheme and that it is all the more important that the analyst examine the weights used the composite weights used. Since it is possible that an unrealistic weighting scheme could be systemized to affect every DMU rather than just one DMU.

\section{CONCLUSION}

The highest rated location was DMU 5 in all but 2 of the cases examined. The robustness of the selection of DMU 5 agreed with other results but is in large part a function of the exceptionally good performance of this DMU. The relative ranking of the other five locations varied considerably. In the absence of such a particularly strong
DMU, other applications may exhibit more variation in the selection of the "best" DMU.

Each of the DEA extensions used: weight restrictions, superefficiency, and cross-efficiency has advantages and disadvantages. These techniques introduce important implicit assumptions that should be recognized and addressed directly. It is also possible to use these techniques in various combinations to overcome their limitations.

Selecting whether or not to use one or more of these techniques requires careful consideration by the analyst but may result in a better evaluation.

\section{REFERENCES}

[1] P. Andersen and N. C. Petersen, "A procedure for ranking efficient units in data envelopment analysis," Management Science, vol. 39, pp. 1261-4, 1993.

[2] T. R. Anderson and K. B. Hollingsworth, "An introduction to data envelopment analysis in technology management," in Proceedings of PICMET'97, D. F. Kocaoglu, T. R. Anderson, K. Niwa, D. Milosevic, and M. J. Gregory, Eds. Portland: PICMET, 1997.

[3] A. Chames, W. W. Cooper, Q. L. Qei, and Z. M. Huang, "Cone ratio data envelopment analysis and multi-objective programming," International Journal of Systems Science, vol. 20, pp. 1099-118, 1989.

[4] A. Chames, W. W. Cooper, and E. Rhodes, "Measuring the efficiency of decision making units," European Journal of Operations Research, vol. 2, pp. 429-44, 1978.

[5] J. Doyle and R. Green, "Data envelopment analysis and multiple criteria decision making," Omega, vol. 21, pp. 713-715, 1993.

[6] J. Doyle and R. Green, "Efficiency and cross-efficiency in DEA: derivations, meanings and uses," Journal of the Operational Research Society, vol. 45, pp. 567-578, 1994.

[7] R. G. Dyson and E. Thanassoulis, "Reducing weight flexibility in data envelopment analysis," Journal of the Operational Research Society, vol. 39 , pp. 563-76, 1988 .

[8] R. Green and J. Doyle, "Improving discemment in DEA using profiling: a comment," Omega, vol. 24, pp. 366-366, 1996.

[9] T. R. Sexton, R. H. Silkman, and A. Hogan, "Data envelopment analysis: critique and extensions," in Measuring Efficiency: An Assessment of Data Envelopment Analysis, vol. 32, New Directions for Program Evaluation, R. H. Silkman, Ed. San Francisco: American Evaluation Association, Jossey Bass, Inc., 1986.

[10] T. J. Stewart, "A critical survey on the status of multiple criteria decision making theory and practice," Omega, vol. 20, pp. 569-586, 1992.

[11] T. J. Stewart, "Data envelopment analysis and multiple criteria decision making: a response," Omega, vol. 22, pp. 205-206, 1994.

[12] R. G. Thompson, F. D. Singleton, Jr., R. M. Thrall, and B. A. Smith, "Comparative site evaluations for locating a high-energy physics lab in Texas," Interfaces, vol. 16, pp. 35-49, 1986.

[13] C. Tofallis, "Improving discemment in DEA using profiling," Omega, vol. 24, pp. 361-364, 1996. 